Article

\title{
Examination of Green Building Drivers in the South African Construction Industry: Economics versus Ecology
}

\author{
Abimbola Olukemi Windapo \\ Department of Construction Economics and Management, University of Cape Town, \\ University Avenue South, Rondebosch 7701, South Africa; E-Mail: abimbola.windapo@uct.ac.za; \\ Tel.: +27-21-650-2049; Fax: +27-21-689-7564
}

Received: 10 June 2014; in revised form: 26 August 2014 / Accepted: 27 August 2014 /

Published: 9 September 2014

\begin{abstract}
There is a large body of literature on green buildings, but few studies have focused on the motivation behind the construction of green buildings globally, and in South Africa in particular. This paper investigates the key drivers of green building in the Western Cape Construction Industry of South Africa and examines whether these drivers have changed over time. A comprehensive literature review was undertaken to provide an overview of green building issues globally and in South Africa, followed by an empirical investigation into the drivers of green building in South Africa using a multi-case study approach. The findings reveal that the key drivers of green building include rising energy costs, the industry's Green Star rating system, competitive advantages and legislation. The study also indicates that these key drivers have not changed significantly over time. Taken together, these results suggest that the increase in green building has little to do with ecological factors and more to do with economic factors-operational costs and stakeholder demands. The paper concludes that as long as the cost of energy continues to increase and there are recognised industry rating systems in place, the need for green buildings is likely to remain.
\end{abstract}

Keywords: building codes; competition; construction; ecology; energy costs

\section{Introduction}

This paper investigates the drivers of green building within the Western Cape Construction Industry of South Africa. The Green Building Council of South Africa (GBCSA) defines a green building as a resource-efficient, energy-efficient, and environmentally responsible building that reduces its direct 
and indirect impact on the environment throughout its life, from the beginning of construction, during occupancy, and when it is later demolished [1]. According to Prouty and Glover [2], "Green" Building is a term that, in only a few years, has moved from obscurity to the headlines. McGraw Hill [3] defines green building as a construction project that is either certified under any recognised global green rating system or built to qualify for certification and posits that green building is a relatively new concept in South Africa, lagging behind the major markets of Europe, the United States, Australia, Asia, and the United Arab Emirates. However, McGraw Hill's research indicates that green building is rapidly taking hold in South Africa and is growing at a faster rate than in any other part of the world. By 2015, according to the McGraw-Hill Construction smart market report, it is expected that $51 \%$ of all firms in South Africa will achieve high levels of green building activity, which is more than triple the $16 \%$ in 2012, and that green building will become the norm within the construction industry. A high level of green activity is achieved when more than $60 \%$ of the work undertaken by a company is green. According to Bond and Perrett [4], although green construction faces the ups and downs of the broader construction cycle, the drivers of green building are expected to increase its market share. The drivers, however, remain undefined.

An early recognition of sustainable development principles can be observed in early human civilisations, such as the South African Bushmen, who knew that they were dependent on the Earth's life support system and would need to use the resources provided by nature at a sustainable rate [5]. Over time, as people have advanced in both technological and scientific knowledge, they have thereby increased their ability to affect planetary systems. Activists, such as Carson (1962) and Leopold (1949), called for a widespread effort to minimise the impact that material- and energy-intensive developments had on the environment [6]. A United Nations conference held in Stockholm in 1972 marked the first occasion on which sustainable development was recognised as an international concern. The idea of eco-development that emerged sought to achieve social and economic objectives through environmentally friendly management. Eco-development preceded the term sustainable development [7].

In areas of high construction activity, the United Nations advocates for sound planning; appropriate allocation and management of water and land use; and environmental management plans to be implemented for all construction activities to aid in the conservation of biodiversity [8]. According to Katz [9], energy consumption within the construction industry and the operation of offices and factories and other buildings is higher than any other human activity (citing the United States Energy Information Administration (EIA) figure that buildings account for $38 \%$ of $\mathrm{CO}_{2}$ emissions and $73 \%$ of electricity consumption in the USA, respectively). In addition, Augenbroe et al. [10] estimate that 50\% of all global resources are consumed by the construction industry, representing six billion tons of raw industrial materials each year. Morris [11] notes that architects today attempt to combine old and new technologies to achieve a design with minimal environmental impact and low operating costs that also offset the higher upfront cost of green building. Cruyenwagen [12] estimated that the added cost of green building is approximately $7.5 \%$ of the total construction costs.

Based on the research described above, the motivation for building green remains unclear. It is not known whether green building is driven by pure ecology and the need to prevent environmental degradation or by economics - stakeholder demands for low operating costs and competitive advantage. Ecology is the study of life at home, with emphasis on the totality or pattern of relationships between organisms and their environment, whereas economics focuses on management 
of the household [13]. According to Odum and Barrett [13], there are perceived differences between ecology and economics, including in the areas of currency, technological approach, system services and futuristic goals. They contend that human beings tend to consider natural goods and services to be free, such that these goods and services have no value in current market systems. Furthermore, the drivers of green building in South Africa are unknown, and it is not known whether these drivers have changed over time. It is this knowledge gap that the present paper intends to fill. To that aim, the paper first presents a literature review on the drivers of green building and stakeholder preferences. Then, it outlines the findings of a multi-case study of three certified green buildings in the Western Cape Province of South Africa. Finally, it discusses the results of the case study and the implications for possible drivers of green building projects.

\section{Overview of Green Buildings}

This section reviews the concept of green building. It examines the need for green building; drivers of green building; key stakeholders in the green building process; and green initiatives available, both globally and in South Africa.

\subsection{The Concept of Green Buildings}

According to Hassan et al. [14] and Kolev [15], a green building is designed and constructed in a way that is measurably less harmful than traditional buildings to the environment and to the occupants. In essence, green buildings attempt to solve measurable problems associated with conventional buildings. Kolev [15] emphasises that a green building should be designed to use fewer resources and be more durable and recyclable once it has served its purpose.

\subsection{The Need to Build Green}

An increase in the awareness of energy inefficiency and global climate change has significantly impacted the construction sector in recent years [16]. In June 2013, six new buildings in South Africa received a Green Star SA rating from the Green Building Council of South Africa (GBCSA) [2]. A total of 36 buildings have received a Green Star rating since the establishment of the council, demonstrating that green building is rapidly gaining ground in South Africa [1,3]. According to research undertaken by McGraw Hill [3], 51\% of all firms in South Africa are expected to be building at high levels of green activity (that is, more than $60 \%$ of the work undertaken by companies will be green), which is more than triple the current rate of $16 \%$. The World Green Building Council (WGBC) reports that 17 countries worldwide have official Green Building Councils and that membership is increasing [17].

The need for green buildings has been attributed to the deterioration of the environment in recent decades [18], including increased carbon dioxide emissions evident in the melting of the Polar ice caps [19] or global warming. The Kyoto protocol was implemented on 16 February, 2005, to reduce greenhouse gas emissions by 5.2\% below the 1992 levels between 2008 and 2012 [20]. The building industry is identified as contributing approximately $35 \%$ of the world's carbon emissions [21]. 


\subsection{Drivers of "Green” Buildings}

Previous studies have identified numerous possible drivers of green building. Kibert [22] cites the rapid infiltration of the Leadership in Energy and Environmental Design (LEED) green building rating system, an increase in green building council membership, government, and private sector incentives, strong government leadership, an expansion of state and local green building programs and advances in the green building technology as drivers for green building in the USA. Bond and Perrett [4] find the main drivers for sustainable development of commercial property in New Zealand to be environmental impact, followed by tenant demand, financial benefits, corporate social responsibility, and beliefs held by individuals. Bond [23], citing a survey commissioned by the Green Building Council of Australia (GBCA) in 2008, notes that nearly half of the study respondents indicated that tenant demand is driving involvement in green buildings, despite the tenants' unwillingness to pay extra to lease a Green rated building. Another driver noted by Bond was that investors might seek proof that their assets are green star rated because of the perception that one may not be able to sell or lease a building that lacks a green star rating in the future.

The above discourse provides evidence of two arguments related to the need for and drivers of green building. The first argues that green building projects are driven by a need for environmental sustainability and other ecological factors, whereas the second argues that green buildings are driven by economics - the need to reduce the cost of building operations after construction to provide financial savings and competitive advantage. There is, however, no empirical evidence of the key drivers, and no previous study has examined the basis for the construction of green buildings in South Africa. The four main drivers of green building examined in this study are situated between economic and ecological/societal concerns, as depicted in Figure 1.

Figure 1. Four main drivers of green building.

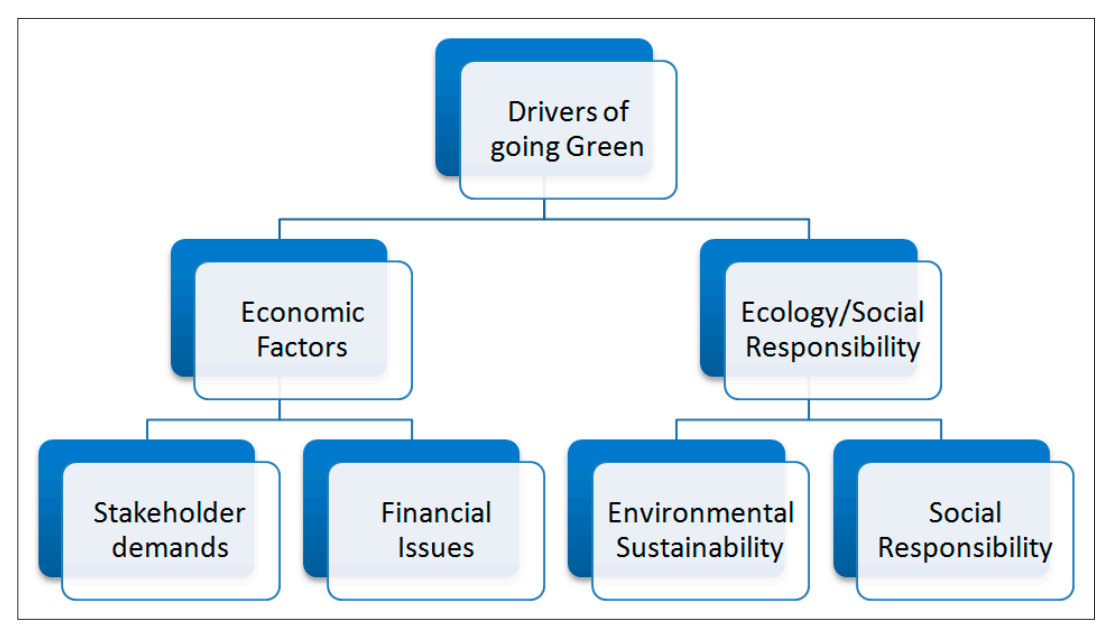

According to Odum and Barrett [13], economics and ecology are intrinsically linked. While economics views currency as money, the technological approach as high technology, system services as services provided by economic capita, and progress as exploration and expansion, ecology views these features as energy, appropriate technology, services provided by natural capital, and sustainability and stability, respectively. This concept is useful in understanding drivers of green building. 
The drivers outlined in literature can be categorised as (1) Economic: stakeholder demand-government, developers, green building councils, building materials manufacturers and tenants - need to reduce building operating costs and acquire a competitive advantage; financial benefits of green building as a result of various incentives and reduced operating costs; and (2) Ecological/Societal: reduced environmental impact/need for environmental sustainability and the need for corporate social responsibility. Each of these drivers is examined below.

\subsubsection{Demand by Stakeholders}

Bond [23] found that nearly half of the stakeholders queried in a survey commissioned by the GBCA indicated that tenant demand is driving their involvement with green building, despite the tenants' unwillingness to pay extra to lease a Green rated building. Investors also believe that it may be difficult in the future to sell or lease a building that is not Green star rated, and this motivates them to build green [23].

In addition, the Vancouver Economic Development Commission (VEDC) [24] posits that the green building sector has considerably transformed over the last decade. Two possible reasons for this include strong government leadership [22] and new policies and rating systems, such as Leadership in Energy and Environmental Design (LEED) [25]. According to US Green Building Council (USGBC) [26], within three years of the LEED rating system's launch, three percent of new commercial projects had registered for certification.

\subsubsection{Financial Benefits of Going Green}

Researchers in one study argued reduced operating costs are a primary motive for green building [27]. This is corroborated by other studies indicating that companies that pursue green initiatives, such as reducing the energy consumed, are able to reduce energy-related operating costs [28,29].

\subsubsection{Reduced Environmental Impact}

Goals such as reducing a building's environmental impact, decreasing the building's contribution to greenhouse gas emissions, and providing a healthier work environment for occupants often factor into the decision to build a Green rated building [30]. According to Kats [31], a green building uses resources such as land, energy, water and materials much more efficiently than does a conventional building, and with the prevalent use of natural lighting and improved indoor air quality, it contributes to the overall health, comfort, and productivity of its occupants.

\subsubsection{Need for Corporate/Social Responsibility}

Tzschentke et al. [26] posit that green construction practices are often adopted for ethical reasons and to fulfil moral obligations, though they raise construction costs in most cases.

\subsection{Key Stakeholders in the Green Building Process}

The key stakeholders and their respective roles in the green building process are described in this section. 


\subsubsection{The Professional Team and their Involvement in Green Building}

The construction industry comprises many key players and distinct trades [32]. According to Elforgani and Rahmat [33], architectural, mechanical and electrical designs are the most influential in the "green" building design process because these systems affect the building envelope, choices of materials and energy efficiency. They further argue that the limited involvement of other industry stakeholders in the design process can influence the performance of green designs. According to Buys et al. [29], although contractors play an important role in green building, due to their involvement in the project delivery system and contract specifications, a contractor's involvement in the design process is often limited. Buys et al. [29] note, for example, that a contractor can play a role in "green" building by recycling and reusing construction debris, limiting the use of hazardous materials, protecting vegetation and using more efficient production systems. Integrated procurement systems (e.g., design and build, turnkey, engineer, procure and construct (EPC)) would, however, permit contractors to participate more actively in green building design.

\subsubsection{The Green Building Council}

The mission of the Green Building Council of South Africa (GBCSA) is to promote development and encourage green building practices through market-based solutions [1]. The establishment of the GBCSA and the progressive development of the Green Star SA rating tool (the green building rating system in South Africa, which established green building standards and provides clear guidelines on what constitutes a green building) have provided the industry with an initial framework for financing, developing and investing in sustainable buildings.

\subsubsection{Private and Public Sector Clients}

According to the Construction Industry Development Board (CIDB) [34], the South African Government is dedicated to reducing greenhouse gas emissions through a variety of mechanisms such as green building. This commitment was evident at the COP17 climate change meeting, which South Africa hosted. South Africa aims to reduce its greenhouse gas emissions by $34 \%$ by 2020 and $42 \%$ by 2025 [34]. The South African government and non-government entities are taking steps toward a green construction industry. To assist with its green building commitment, the South African government adopted a National Framework for Green Building in South Africa (NFGBSA) as its official green building in November 2011. A key strategy of the NFGBSA is to develop green building regulations and standards [35]. The South African government has enacted the SANS 10400 and Part XA of the Building Regulations to guide the design and construction of green buildings in South Africa.

\section{Research Methodology}

This chapter describes the research methods for the present study and the approach that was followed to fulfil the research objectives. 


\subsection{Research Philosophy, Paradigm and Approach}

The objectives of this research project were to identify the drivers of green building projects and examine whether those drivers have changed over time. These objectives led to the hypothesis that the key drivers of green building have indeed changed over time and that they have trended toward economic rather than ecological factors. A descriptive case study research design was used. A case study is an empirical inquiry, which is used to investigate multiple types of data, such as interviews and academic literature, within their real-life context [36]. The case study allows researchers to explore individuals, organisations, communities and programs, to test research mechanisms and techniques [37], and to explore a phenomenon in context using a variety of data sources [38]. A multiple case study design, consisting of a replication approach (rather than sampling logic) to three cases, is used in this article [38]. Figure 2 illustrates the multiple case study process.

Figure 2. Replication approach to multiple case studies (after [36]).

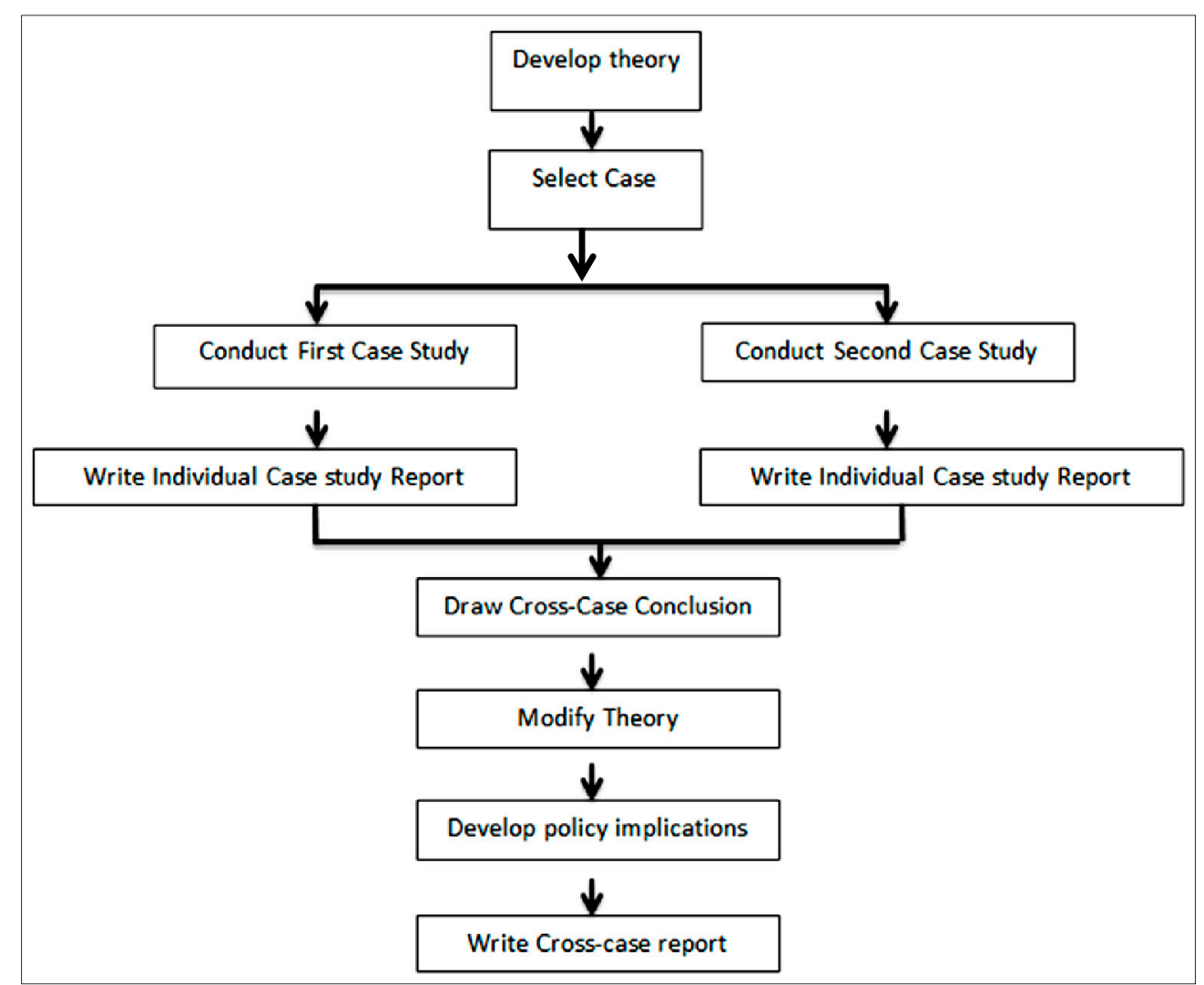

The three case studies were selected based on whether the buildings had been certified as Green by the Green Building Council of South Africa (GBCSA), the date of certification, and ease of access to information. The population from which the study sample was drawn consisted of seven buildings located in the Western Cape Province of South Africa. Interviews were conducted with professional team members (Architect, Engineers - mechanical, electrical, structural and quantity surveyors) who were involved in the construction of each building (A, B, and $\mathrm{C}$ ), as shown in Table 1. A total of 15 respondents were interviewed. It was determined that the consultants who provide design and construction solutions utilising green design standards would be better suited to assess the drivers of green building from the perspective of their clients, the GBCSA and green building legislation. 
Table 1. Interview Respondents.

\begin{tabular}{ccccccc}
\hline \multirow{2}{*}{$\begin{array}{c}\text { Case } \\
\text { Study }\end{array}$} & Architect & $\begin{array}{c}\text { Structural } \\
\text { Engineer }\end{array}$ & $\begin{array}{c}\text { Civil } \\
\text { Engineer }\end{array}$ & $\begin{array}{c}\text { Mechanical } \\
\text { Engineer }\end{array}$ & $\begin{array}{c}\text { Quantity } \\
\text { Surveyor }\end{array}$ & Total \\
\hline A & 1 & 1 & 1 & 1 & 1 & 5 \\
B & 1 & 1 & 1 & 1 & 1 & 5 \\
C & 1 & 1 & 1 & 1 & 1 & 5 \\
Total & 3 & 3 & 3 & 3 & 3 & 15 \\
\hline
\end{tabular}

\subsection{Method of Data Collection}

A structured interview and a site visit approach (visual inspection) were used in data collection. Personal interviews were held with 13 respondents using an interview protocol. The interview questions were emailed to two additional respondents who were not available to be interviewed. These additional respondents printed and filled out the questionnaire before scanning and returning the answered sheets. The interview protocol consists of 11 questions (see the Appendix for a sample protocol). The first 6 questions relate to the respondent or interviewee's personal information such as the respondents name, title, profession, employer, the certified green building project that the respondent worked on and the year the building was certified as green. These questions were included to assess each respondent's role in the construction industry and, more specifically, in the green certified building being studied. The interview did not limit the way in which each question could be answered, but each question was accompanied by a list of answers that could be selected to standardise across respondents. The standardisation enabled straightforward comparison and a focus on the essential aspects of this research. Site visits were undertaken to obtain a greater understanding of the building and the key features that contributed to its green star rating. Each case study building was visited twice.

\subsection{Method of Data Analysis}

The data were analysed using a thematic analytical technique. Rather than being rooted in theory, this technique is centred on developing categories based on participant responses and the resulting data [39]. Thematic analysis identifies themes and patterns in recorded conversations. The patterns may be drawn from direct quotations and/or by summarising general thoughts of the interviewees. Then, data related to these patterns were identified, and similar patterns were combined into sub-themes. By analysing the themes that emerge from the summarised data, a broad view of the information can be formed [40]. A comparative analysis of all three case studies was also undertaken. Written consent to use the interview responses was obtained from each respondent. The research is limited, however, in that the data collected centres around the perceptions and personal biases of the interviewees. Cross-case conclusions were drawn to minimise this limitation.

\section{Results and Discussion}

This section presents an analysis of the case study data. The chapter is comprised of quotations and other extracts from the interviews. A brief introduction of each case study is presented before moving 
on to the analysis. To maintain the confidentiality of the participants, the case studies are designated A, $\mathrm{B}$, and $\mathrm{C}$ (Table 1).

\subsection{Interview Summaries}

\subsubsection{Case Study A}

Building A earned a 4 Star Green Star SA-Office Design v1 rating. It was certified as a green building in 2013 by the GBCSA. Building A is located in the Cape Town central business district and occupies an entire city block. The Electrical Engineer, Civil Engineer and Architect were interviewed. The interviews indicated that the respondents perceive the public and government to be reasonably interested in green building. For example, respondents stated that green building is not fully understood by the public or the government. They cited rising energy costs, tenant demand, availability of the industry (Green Star) rating system, competitive advantage and company image as the key drivers of incorporating green building principles into the project. Healthy indoor air quality was considered the least important driver for this project.

\subsubsection{Case Study B}

Building B has all of the features of a green star rated building, but it was not certified as a green building to avoid the added cost of certification. The consultants interviewed all mentioned both that the project was not certified and that Building B was the first green built/designed building in the Western Cape Province of South Africa. The interviewees felt that the current state of green building in South Africa was mediocre but noted that new legislation regulating energy consumption could stimulate the industry. They opined that the market is not sufficiently large to enable the competitive costs of green building elements. The architect in particular felt that the government has very little interest and shows a general lack of commitment to green building, citing the ongoing development of suburban housing, a large source of carbon dioxide, and a failure to enact "separated at source" waste management regulations.

The interviewees identified rising energy costs, financial benefits of reduced energy consumption, building codes, tenant satisfaction and competitive advantage as drivers of green features of the project. Notably, the architect further stated that

"companies and individuals feel that it is of great[er] importance to be considered 'green' than to actually be 'green'. He views that while there is a clear realisation to create a sustainable environment, the fact is that costs still motivate consumer decisions".

Furthermore, the interviewees perceived healthy indoor air quality to hold little importance to a client interested in green building because this feature is also achievable for conventional buildings.

\subsubsection{Case Study C}

In 2011, the GBCSA awarded building C a 5 Star Green Star SA-Office Design v1 rating in 2011, the first of its kind in South Africa. The respondents perceived that the market for green buildings is reasonably developed in South Africa because commercial office developers and government 
departments have embraced it, but its uptake has been slow in other spheres. They also considered that the government is quite interested and has strongly promoted "green" building through the SANS 10400 and Part XA of the building regulations.

The interviewees indicated that the main driver of the green features of Building $\mathrm{C}$ was to boost its public image by building the first 5 star rated building in Cape Town. Other primary drivers identified include lower lifecycle costs, rising energy costs and the availability of an industry (Green Star) rating system. One of the interviewees added that:

"the most important driver in the Western Cape at the moment is for private developers to beat their competitors, because even though 'green' building is good, we live in a world where everything is about money and beating the rest".

The interviewees also indicated that they considered marketing potential and increased rent to be important benefits of green buildings and healthy indoor air quality to be the least important among the drivers of green building. They also perceived ventilation as the most costly aspect of green buildings because natural ventilation is almost impossible in large buildings without the aid of large air conditioners, adding that it is expensive to design an energy-efficient air conditioner.

\subsubsection{Comparative Analysis of the Interviews}

Most of the professionals interviewed believe that green building is at an early stage in South Africa and that it is yet to develop, although a few believe that green building is reasonably well developed. With regard to public interest, interviewees across the case studies expressed contrasting views, but most believe that the public is not interested in green buildings. Most of the professionals agree that the government shows little interest, pointing to more pressing issues the government faces. In contrast, the respondents who perceive some government interest cite implementation of the SANS 10400 and Part XA of the building regulations as evidence. In addition, all but one of the professionals interviewed identified ventilation as the costliest aspect of green building.

All respondents also identified rising energy costs and the industry (Green Star SA) rating system as the key drivers of green building. In addition, a large number of respondents view competitive advantage and building codes as primary drivers of green building. Both of these drivers are aspects of stakeholder demand that are related to economics. Most respondents also view operational cost savings, along with marketing potential, as major benefits of green building. One respondent, however, did not share the view that operational cost saving is an important factor, and another disagreed that green building is a marketing tool. Respondents almost unanimously do not view healthy indoor air as an important driver. Increased rent and property value are each considered important by most but not all of the respondents. Notably, the architects in particular indicated that increased rent and property value are not important benefits of green building. According to one architect,

"the item of increased property value is of little importance as the value of the property is location specific." 


\subsubsection{Trends in Green Building Projects}

Further analysis revealed that Building A was constructed and certified in 2013, Building B was constructed in 2006 and Building $C$ was constructed and certified in 2011. While the key drivers of green building identified with regard to the project constructed in 2013 include rising energy cost and the industry (Green Star) rating system, the key drivers of the 2011 project were identified as rising energy costs, building codes and the industry (Green star) rating system. For the 2006 project, the key drivers were also identified as rising energy costs, building codes and the industry (Green star) rating system. Thus, it can be observed from the case studies that that the drivers of green building have not significantly changed over time (i.e., the period of 2006 to 2013).

\subsubsection{Themes Drawn from Interviews}

The following themes emerged from the case study interviews:

- Green building is at a premature stage in South Africa, with the public and the government showing little interest in the subject;

- Rising energy costs (financial aspects) and the industry (Green Star) rating system (subset of stakeholder demand) are considered the primary drivers of green buildings;

- The green star certification system in South Africa appears to be reasonably developed from the perspective of professionals in the industry;

- Operational cost savings, along with marketing potential and the ability to charge higher rents, are all considered generally important benefits, whereas healthy indoor air quality is almost unanimously considered unimportant;

- The costliest aspect of green building is the ventilation system;

- The widespread incorporation of green features in buildings is possible, and the key driver is perceived to be the increase in rebates/subsidies for green investments;

- The drivers of green building have not changed since 2006.

According to the literature, stakeholder demand [22,23,25], financial benefits [27-29], reduced environmental impact [30,31], and demand for corporate social responsibility (people's beliefs) [23] are the main drivers of green building. Similarly, the interviews indicated rising energy costs (financial benefits), followed by the industry (Green Star) rating system are the main drivers of green buildings. The case study findings support the literature in three main areas - stakeholder demand, the industry rating system, and financial incentives, as well as environmental considerations, to a lesser extent. Overall, the results suggests stakeholder decisions are driven more by economics than by environmental or social sustainability, supporting the view of one of the respondents, who said:

"companies and individuals feel that it is of great[er] importance to be considered 'green' than to actually be 'green"”.

The green building industry is driven largely by public perception and the associated financial gains. The case studies also suggest that government policies and the development of an appropriate rating system, Green Star SA, have stimulated the development of green buildings in South Africa. This supports earlier findings by Kibert [22], who established that the enactment of policies and 
rating systems, such as LEED, have encouraged green buildings in the USA. One respondent summarised this view by stating, "[a] change of legislation would [have] a very big impact...[on] the uptake of 'green' buildings".

\section{Conclusions}

This study examined the key drivers of green buildings in the Western Cape construction industry and whether these drivers have changed over time. The study used a multi-case study approach to collect empirical data. The data indicated that the key drivers of green buildings are rising energy costs and the attendant need to reduce building operating costs, as well as the availability of an appropriate rating tool, i.e., the Green Star SA rating system. It was also found that the drivers of green buildings have not changed significantly over the period 2006-2013. Rising costs and the availability of an appropriate rating tool have remained constant as the key drivers of green buildings. Based on these findings, it can be concluded that the main drivers of green buildings are financial rather than environmental. The green accreditation provided by the Green Star rating tool has enabled developers to portray their buildings as green and therefore, gain a competitive advantage and a new marketing tool. The data suggest that in the absence of a standard rating tool capable of conferring "greenness" on a building, along with competitive advantage, corporate image, and product differentiation, green building would be less attractive. The financial benefits of green building are similarly linked to the standard rating tool.

It can also be concluded that without a sound business or economic case, such as downstream financial benefits due to reduced operating costs and higher rental income, and without government regulations to support the construction of green buildings, very few clients would develop green buildings for the sole purpose of environmental sustainability. This study recommends that the South African government implement legislative measures and building regulations in support of green building design and construction. It is further recommends that countries without green rating systems in place consider developing one. Green building legislation would supply the vehicle necessary to institute requirements, and the rating system would provide the impetus.

This research is limited by its small sample size and the location-specific nature of the multi-case study approach. Nonetheless, it provides factual evidence of the drivers of green building and whether those drivers have changed over time. It is not expected that the motivations for building green would change significantly between projects and geographical locations, but future studies of green building projects in other locations could validate these results.

\section{Acknowledgments}

The author would like to acknowledge, with thanks, the assistance of the following people in conducting the survey: Sharifa Abdurahman, Umar Manack, and Deen Joseph. 


\section{Appendix: Interview Protocol}

Name:

Position:

Company:

Project:

Year certified green:

Your participation in this research is highly appreciated.

The research examines the drivers of Green Building within the Construction Industry of South Africa.

The purpose of this interview is to identify the key drivers of Green Building in the Western Cape Construction Industry, and examine whether these drivers have changed with time.

The findings of this interview and your input will be used for academic purposes only and your response will be confidential.

1. How would you characterise the current state of the "Green" Building industry in South Africa? (1 $=$ not developed, $5=$ fully developed)
○ 1
○ 2
○ 3
○ 4
○ 5

Reason:

2. How would you characterise the public's interest in green building in South Africa? $(1=$ not interested, 5 = strongly interested)
○ 1
○ 2
○ 3
○ 4
$\circ 5$

Reason: 
3. How would you characterise the Government's interest in green building in South Africa? $(1=$ not interested, 5 = strongly interested)
○ 1
○ 2
○ 3
○ 4
○ 5

Reason:

4. Rank the following drivers of this green building development from 1(most important) to 10 (least important).

- Tenant satisfaction and productivity

- Competitive advantage

- Lower lifecycle costs

- Superior building performance

○ Rising energy costs

- Government policy

- Building code

○ Industry rating system (Green Star)

- Increased education

- Greater availability of green products

Reason:

5. Indicate the reasons why the company represented is involved in green building:

- Financial incentives and/or subsidies

- Financial benefits/reduced costs/increased property value

- Tenant demand

- Financier requirement

- Company image

- Personal beliefs 
○ Regulations

○ Corporate Social Responsibility

○ Benefit to the environment

Reason:

6. How would you characterise the current status of the Green Star certification system in South Africa? ( 1 =Not developed, 5 =Well developed $)$
○ 1
○ 2
○ 3
○ 4
○ 5

Reason:

7. Is there a need for increased education of the professional team, property managers and client in the management of Green Star certified properties

○ Yes

○ No

If yes should the Green Building council be responsible for this training, why?

8. If it were to cost more to incorporate "green" features into a building, what in your opinion, would the client consider being important financial and non-financial benefits? Please rank these from 1 (most important) to 7 (least important) with a brief explanation beside each answer.

○ Occupancy cost savings

- Increased property value

○ Decreased obsolescence

- Healthy indoor air quality

$\circ$ Increased rent 
○ Marketing potential (i.e., enhanced building or company image)

Reason:

9. What are you as a construction industry professional doing now with regard to going green compared to what you did before?

Reason:

10. In your opinion, what else can be done to enhance the uptake and incorporation of energy/water saving (or generating) features into the design of new buildings?

Please rank these from 1 (most important) to 8 (least important) with a brief explanation beside each answer.

Building code changes

More rebates/subsidies

Better advertising

Change in legislation

Building certification

Availability of products

Mandatory energy efficiency reporting

Other (specify) 
11. Does your company plan to become involved in green building in the future?
○ Yes
○ No

\section{Conflicts of Interest}

The author declares no conflict of interest.

\section{References}

1. GBCSA. Available online: http://www.gbcsa.org.za (accessed on 2 April 2013).

2. Prouty, E.; Glover, E. The Green Building Boom Continues-Profiting from the Green Building movement. Available online: http://srmnetwork.com/pdf/whitepapers/Green_Building_Boom_ Continues_Jul10.pdf (accessed on 4 March 2013).

3. McGraw-Hill. World Green Building Trends; Smart Market Report; McGraw-Hill: New York, NY, USA, 2013.

4. Bond, S.; Perrett, G. The key drivers and barriers to the sustainable development of commercial property in New Zealand. J. Sustain. Real Estate 2012, 4, 48-77.

5. Van der Post, L.; Taylor, J. Testament to the Bushmen; Viking: New York, NY, USA, 1984.

6. Hill, R.C.; Bowen, P. Sustainable construction: Principles and a framework for attainment. Constr. Manag. Econ. 1997, 15, 223-239.

7. Gardner, J. Decision making for sustainable development: Selected approaches to environmental assessment and management. Environ. Impact Assess. Rev. 1989, 9, 337-366.

8. IUCN; UNEP; WWF. World Conservation Strategy; World Conservation Union: Grand, Switzerland; United Nations Environment Programme: Nairobi, Kenya; World Wide Fund for Nature: Grand, Switzerland, 1980.

9. Katz, A. Green Buiding Facts; United States Green Building Council: Washington, DC, USA, 2012. Available online: http://www.usgbc.org (accessed on 30 March 2013).

10. Augenbroe, G.; Pearce, A.R.; Guy, B.; Kibert, C.J. Sustainable construction in the United States of America. In Proceedings of the CIB-W82 World Congress, Gaevle, Sweden, 7-12 June 1998. Available online: http://mac.com (accessed on 18 May 2011).

11. Morris, P. What does green really cost? Available online: http://69.63.147.133/legalresources/ publications/greenhousecounsel/upload/Morris-Article.pdf (accessed on 18 May 2011).

12. Cruywagen, J.H. The cost of "going green"-A case study. In Proceedings of the Green Vision 2020, 6th Annual SACQSP Research Conference, Cape Town, South Africa, 20-21 June 2013.

13. Odum, E.P.; Barrett, G.W. Fundamentals of Ecology, 5th ed.; Brooks-Cole: ForestLodgeRoad, CA, USA, 2005.

14. Hassan, A.S.; Laul, A.; Shah, K.; Adebayo, A.; Ebohon, O.J.; Irurah, D.K.; Rwelamila, P.D.; Agopyan, V.; Arruda, M.P.; John, V.M.; et al. Agenda 21 for Sustainable Construction in Developing Countries, WSSD ed; CSIR Building and Construction Technology: Pretoria, South Africa, 2002.

15. Kolev, M. EcoBuilding and Job Creation. In Green Building Handbook for South Africa; CSIR Built Environment: Pretoria, South Africa, 2009. 
16. Hoffman, D.; Pienaar, H. Current trends in green star design strategies in Australia, New Zealand and South Africa. In Proceedings of the Green Vision 2020, 6th Annual SACQSP Research Conference, Cape Town, South Africa, 20-21 June 2013.

17. World Green Building Trends SmartMarket Report. Available online: http://www.worldgbc.org/.../ World_Green_Building_Trends_SmartMarket_Report (accessed on 4 March 2013).

18. Van der Merwe, C. South Africa's built-environment professionals begin to embrace green-building practices. Available online: http://www.worldgbc.org/ (accessed on 30 March 2013).

19. Hassol, S.J. Arctic Climate Impact Assessment: Impacts of a Warming Arctic, 2nd ed.; Cambridge University Press: Cambridge, UK, 2005.

20. Cheng, C.; Pouffary, S.; Svenningsen, N.; Callaway, M. The Kyoto Protocol, the Clean Development Mechanism and the Building and Construction Sector-A Report for the UNEP Sustainable Buildings and Construction Initiative; United Nations Environment Programme: Paris, France, 2008.

21. Harrison, A.J.W. Making recycling economic - The sustainability of materials for the built environment. In Construction Demolition Waste, 1st ed.; Limbachiya, M.C., Roberts, J.J., Eds.; Thomas Telford Publishing: Cornwall, UK, 2004; pp. 375-400.

22. Kibert, C.J. Sustainable Construction: Green Building Design; Wiley \& Sons, Inc.: New Jersey, NJ, USA, 2012.

23. Bond, S. Best of the Best in Green Design: Drivers and Barriers to Sustainable Development in Australia; Lincoln University Digital Dissertation: Cantebury, UK, 2010.

24. Vancouver Economic Development Commission (VEDC). Green Buildings in Vancouver, 2009. Available online: http://www.vancouvereconomic.com/userfiles/file/green-building-profile.pdf (accessed on 30 March 2013).

25. IGEL. The rapid rise of green building special report. Available online: http://www.igel.wharton.upenn.edu/ (accessed on 21 September 2013).

26. USGBC. Building Momentum-National Trends and Prospects for High Performance Green Buildings; U.S. Green Building Council: Washington, DC, USA, 2003. Available online: http://www.org/Docs/ (accessed on 17 May 2013).

27. Tzschentke, N.; Kirk, D.; Lynch, P. Reasons for going green in serviced accommodation establishments. Int. J. Contemp. Hosp. Manag. 2004, 16, 116-124.

28. Joseph, C. What Are the Benefits of Going Green for a Business? Available online: http://www.smallbusiness.chron.com/ (accessed on 24 May 2013).

29. Buys, F.; Hurbissoon, R. Green buildings: A mauritian built environment stakeholders' perspective. Acta Struct. 2011, 18, 81-101.

30. 2008 Intel Corporate Responsibility Report. Available online: http://www.intel.com/ (accessed on 11 June 2013).

31. Kats, G.H. Green Building Costs and Financial Benefits; Massachusetts Technology Collaborative: Massachusetts, MA, USA, 2003.

32. Allen, J.H.; Potiowsky, T. Portland's green building cluster: Economic trends and impacts. Econ. Dev. Q. 2008, 22, 303-315.

33. Elforgani, M.S.; Rahmat, I. An investigation of factors influencing design team attributes in green buildings. Am. J. Appl. Sci. 2010, 7, Article 7. 
34. CIDB. Best Practice Guide from Best Practice: Project Assessment Scheme; Construction Industry Development Board: Pretoria, South Africa, 2011. Available online: http://www.cidb.org.za/ (accessed on 23 July 2013).

35. Van Wyk, L. IGBC\&E-A national framework for green buildings in South Africa. In Future Trends and Issues Impacting on the Built Environment, Proceedings of the International Green Building Conference and Exhibition, Sandton, South Africa, 25-26 July 2012; pp. 1-8.

36. Knight, A.; Ruddock, L. Advanced Research Methods in the Built Enviroment, 1st ed.; John Wiley and Sons: Hoboken, NJ, USA, 2008.

37. Yin, R. Case Study Research. Design and Methods, 4th ed.; Sage Publications: Thousand Oaks, CA, USA, 2009.

38. Zainal, Z. Case study as a research method. Jurnal Kemanusiaan 2007, 9, 1-6.

39. Fossey, E.; Harvey, C.; McDermott, F.; Davidson, L. Understanding and evaluating qualitative research. Aust. New Zeal J. Psychiatr. 2002, 36, 717-732.

40. Aronson, J. A pragmatic view of thematic analysis. Qual. Rep. 1994, 2, 1-3.

(C) 2014 by the author; licensee MDPI, Basel, Switzerland. This article is an open access article distributed under the terms and conditions of the Creative Commons Attribution license (http://creativecommons.org/licenses/by/3.0/). 